\title{
Influence of Structure on Dye Degradation with Laccase Mediator Systems
}

\author{
EVA ALMANSA ${ }^{\mathrm{a}}$, ANDREAS KANDELBAUER $^{\mathrm{a}, \mathrm{b}}$, LUCIANA PEREIRA $^{\mathrm{a}, \mathrm{c}}$, ARTUR CAVACO-PAULO $^{\mathrm{c}}$ \\ and GEORG M. GUEBITZ ${ }^{\mathrm{a} *}$ \\ ${ }^{a}$ Department of Environmental Biotechnology, Graz University of Technology, Petersgasse 12, A-8010, Graz, Austria; ${ }^{b}$ Department of Applied \\ Research, Funder Industrie Gesellschaft m.b.H., Klagenfurterstrasse 87-89, A-9300 St. Veit Glan, Austria; ${ }^{c}$ Department of Textile Engineering, \\ University of Minho, 4800 Guimaraes, Portugal
}

(Received for publication 16 June 2004; Revised manuscript accepted 29 October 2004)

A new laccase was purified from Trametes hirsuta IMA2002. The laccase had a molecular mass of $62 \mathrm{kDa}$ and an isoelectric point of $\mathrm{pH} 7$. It had an optimum $\mathrm{pH}$ of 3.0 and an optimum temperature of $55^{\circ} \mathrm{C}$. The laccase was quite stable at $30^{\circ} \mathrm{C}$ and $\mathrm{pH} 4.0$ with a half-life of more than 100 hours. On ABTS, syringaldazide, and DMP the laccase showed $K_{M}$ and $K_{\text {cat }}$ values of 75,12 and $37 \mu \mathrm{M}$ and 64,83 and $54 \mathrm{~s}^{-1}$, respectively. The structurally diverse commercial dyes Indigo Carmine, Lanaset Blue 2R, Diamond Black PV 200 and Diamond Fast Brown were oxidized by the laccase. While the rate and extent of decolorization of the latter dye was significantly enhanced by the presence of different types of mediators, the structurally similar azo-dye Tartrazine was not oxidized. Lanaset Blue $2 R$, a commercial textile dye containing an anthrachinoid structural fragment acted similarly to anthrachinone sulfonic acid by strongly enhancing the rate of the decolorization reaction. Twenty two model azo-dyes based on the molecular framework of 2,7-dihydroxy-1-phenylazonaphtalene-3,6disulfonic acid were synthesized and the kinetics of their laccase-catalyzed decolorization was studied. Hydroxy-substituted dyes were the most susceptible to enzyme/mediator action. All reactions were well described by Michaelis-Menten-like kinetics and the Hammett free energy linear relationship could be successfully applied to describe the influence of dye structure (substituents on the aromatic ring) on decolorization. Strongly electron withdrawing substituents such as a nitro-group in the meta-position $(+0.7)$ resulted in positive $\sigma$-constants whereas electron donating groups such as para-methyl $(-0.3)$ resulted in negative values for $\sigma$-constants.

Keywords: Laccase; Mediators; Bioremediation; Textile Dye decolorization; Enzyme kinetics; Structure - reactivity relationship

\section{INTRODUCTION}

Laccases (benzenediol:oxygen oxidoreductase, EC 1.10.3.2) catalyze the removal of a hydrogen atom from the hydroxyl group of ortho and para-substituted mono- and poly-phenolic substrates and from aromatic amines by one-electron abstraction, to form free radicals, capable of undergoing further depolymerization, repolymerization, demethylation or quinone formation (Thurston, 1994; Yaropolov et al., 1994). The rather broad substrate specificity of laccases may be additionally expanded by addition of redox mediators such as ABTS, HBT, TEMPO (Fabbrini et al., 2002), polyoxometalates (Tavares et al., in press) and osmium-based redox polymers (Barriere et al., 2004) or compounds secreted by lignolytic fungi (Eggert et al., 1996; Johannes and Majcherczyk, 2000a).

Laccases are involved in the biodegradation of lignins and a great number of white-rot fungi have been reported to produce the lignin degrading enzymes laccase, lignin peroxidases and manganese peroxidases, or at least, one of these enzymes. Based on their natural role in lignin depolymerization laccases can be used for bleaching of wood (Bourbonnais and Paice, 1992; Paice et al., 1995) and nonwood pulps (Camarero et al., 2004).

Laccases have also found several applications in bioremediation. The enzymes render phenolic compounds less toxic via degradation or polymerization reactions and/or cross-coupling of pollutant phenols

* Corresponding author. E-mail: guebitz@tugraz.at 
with naturally occurring phenols (Haars and Huttermann, 1980; Jönsson et al., 1998; Ullah et al., 2000). Several processes using laccases as well as immobilized laccases have been developed for the treatment of phenolic effluents, PAHs (Dodor et al., 2004; Keum and Li, 2004; Rodriguez et al., 2004) and PCBs (Böhmer et al., 1998; D'Annibale et al., 2000; Davis and Burns, 1992).

In textile processing the application of laccases has been suggested for dye bleaching and dyeing effluent treatment (Kandelbauer and Gübitz, in press). For the latter purpose several processes have been developed based on immobilized laccases (Abadulla et al., 2000; Kandelbauer et al., 2004b; Reyes et al., 1999) The potential of laccases from a number of fungi such as Sclerotium rolfsii (Ryan et al., 2003), Trametes modesta (Nyanhongo et al., 2002), T. hirsuta, (Abadulla, et al., 2000) T. versicolor (Blanquez et al., 2004) Pleurotus pulmonarius (Tychanowicz et al., 2004) among others for dye decolorization has been assessed. In these studies, several dyes were only decolorized by laccase when redox-mediators were present. However, until now no systematic data about the relationship between dye structure and effect of redox mediators have been available. Similarly, the effect of dyes and degradation intermediates as redox mediators has been neglected. Thus, this paper aims to elucidate these interrelations by studying decolorisation of various structurally different model dyes in the presence of a purified laccase of Trametes hirsuta and mediators. In crude enzyme preparations, low molecular weight compounds may be present that could act as natural redox mediators and thus interfere with mechanistic studies. Iso-enzymes could cause misleading kinetic effects as well. Therefore, in order to obtain a defined laccase/mediator system which can be studied under known conditions, for all experiments a highly purified enzyme preparation was used. For industrial purposes of course, such extensive purification is not required.

\section{MATERIAL AND METHODS}

\section{Organism and Culture Conditions}

T. hirsuta (IMA2002) is deposited at the culture collection of the Department of Environmental Biotechnology, at Graz University of Technology, Austria. The fungus was usually grown on PDAagar plates for 5 days at $30^{\circ} \mathrm{C}$ and thereafter stored at $4^{\circ} \mathrm{C}$. For enzyme production, $1 \mathrm{~L}$ Erlenmeyer flasks containing $300 \mathrm{~mL}$ of culture medium were used. The growth medium for T. hirsuta contained (per L distilled water) $10 \mathrm{~g}$ wheat bran flakes, $1.5 \mathrm{~g}$ yeast extract, $1.0 \mathrm{~g}$ glucose, $0.25 \mathrm{~g} \mathrm{NH}_{4} \mathrm{Cl}, 0.05 \mathrm{~g}$ thiamine dichloride, $0.25 \mathrm{~g} \mathrm{CuSO}_{4}$ and $100 \mathrm{~mL}$ salt solution. Each flask was inoculated using an agar piece $\left(1 \mathrm{~cm}^{2}\right)$ cut from a 5 day old culture grown on a PDA-plate. The flasks were incubated at $30^{\circ} \mathrm{C}$ on a rotary shaker (130 rpm). After 3 days, $10 \mu \mathrm{M}$ 2,5xylidine was added to enhance laccase production. Samples were taken every day and both protein and laccase activity were determined. Cultures were harvested by centrifugation at $10,000 \mathrm{rpm}$ for 20 min and supernatants were stored at $4{ }^{\circ} \mathrm{C}$. Two experiments were conducted in parallel and triplicate samples were analysed.

\section{Enzyme and Protein Assays}

Laccase activity was determined at $25^{\circ} \mathrm{C}$ by monitoring the rate of oxidation of $350 \mu \mathrm{L}$ ABTS $\left(2,2^{\prime}-\right.$ azinobis(3-ethylbenz-thiazoline-6-sulfonic acid)), in a total volume of $1500 \mu \mathrm{L}$ (succinic acid buffer, $\mathrm{pH}$ 4.5). In this assay, the formation of a green radical cation is followed spectrophotometrically at $430 \mathrm{~nm}$ according to the procedure described by Niku-Paavola et al. (2000). For rapid identification in the course of the purification process, samples of $50 \mu \mathrm{L}$ were mixed in microtiter plates with $50 \mu \mathrm{L}$ of ABTS. Fractions with a green color contained laccase.

Protein was determined by the Lowry method (Lowry et al., 1951) and for rapid identification the Bradford (Bradford, 1976) method from Bio-Rad (USA) was performed in microtiter plates. The Bradford method was also used for protein quantification after the last step of purification to detect the lower protein concentrations. BSA (bovine serum albumin) was used as a standard.

\section{Enzyme Purification}

Cultures of T. hirsuta were harvested after 9 days of growth, filtered and the supernatant was clarified by centrifugation at 10,000 rpm for 20 minutes. After dialysis, the resulting sample $(1 \mathrm{~mL})$ was fractionated by anion exchange chromatography with a $10 \mathrm{~mL}$ QFF column from Amersham Pharmacia Biotech previously equilibrated in $10 \mathrm{mM}$ sodium acetate buffer ( $\mathrm{pH}$ 5.0). Proteins were eluted in the same buffer in a gradient from 0 to $1 \mathrm{M} \mathrm{NaCl}$ at a flow rate of $2 \mathrm{~mL} \mathrm{~min}^{-1}$. Laccase active fractions $(1.5 \mathrm{~mL})$ were pooled and concentrated in a $350 \mathrm{~mL}$ Amicon stirred cell apparatus, YM10 membrane $(10 \mathrm{kDa})$ and dialysed over night against $100 \mathrm{mM}$ citrate buffer ( $\mathrm{pH}$ 5.0).

The resulting sample $(0.1 \mathrm{~mL})$ was fractionated using size exclusion chromatography with a Superdex 75 HR 10/30 column from Amersham Pharmacia Biotech. Fractions $(0.2 \mathrm{~mL})$ were eluted using a $100 \mathrm{mM}$ citrate buffer ( $\mathrm{pH}$ 5.0) containing $100 \mathrm{mM}$ $\mathrm{NaCl}$ at a flow rate of $1 \mathrm{~mL} \mathrm{~min}{ }^{-1}$. 


\section{Gel Electrophoresis}

Sodium dodecyl sulfate polyacrylamide gel electrophoresis (SDS-PAGE) was carried out in $12 \%$ polyacrylamide gels using broad-molecular weight markers from Amersham Pharmacia Biotech as standards. Proteins on the gel were stained with Coomassie Brilliant Blue. Native-PAGE was preformed similarly except that addition of SDS and 2-mercaptoethanol to the gel was omitted. Gels were developed with $1.1 \mathrm{mM}$ ABTS in deionised water until development of a green coloration was visible. Isoelectric focusing (IEF) was carried out with the Mini-PROTEAN 3 cell from Bio-Rad using IEF Ready Gels ( $\mathrm{pH} 5-8$; Biorad) and protein was located by Coomassie Brilliant Blue staining.

\section{Determination of Temperature and $\mathrm{pH}$ Optima and Stabilities}

Optimum temperature for the activity of the laccase was determined by carrying out the standard laccase assay at selected constant temperatures ranging from $25^{\circ} \mathrm{C}$ to $65^{\circ} \mathrm{C}$. In each case the substrate was preincubated at the required temperature. The optimum $\mathrm{pH}$ was determined at a fixed assay temperature of $30^{\circ} \mathrm{C}$ at various $\mathrm{pH}$ values between $\mathrm{pH} 2.2$ and $\mathrm{pH} 7.0$ using Mcllvaine-type constant ionic strength citrate-phosphate buffer. In order to study the thermal stability, diluted enzyme samples (100 $\mathrm{mM}$ succinate buffer, $\mathrm{pH}$ 4.5) were incubated for fixed time periods at $30^{\circ} \mathrm{C}, 60^{\circ} \mathrm{C}, 80^{\circ} \mathrm{C}$. At time intervals the $\mathrm{pH}$ of the incubation mixture was measured and aliquots were withdrawn and were cooled on ice before assaying to determine the residual enzyme activity, using the normal assay procedure. The stability of the enzyme at various $\mathrm{pH}$ values was determined by preincubating the enzyme at the desired $\mathrm{pH}$ for a fixed period at $30^{\circ} \mathrm{C}$. Residual enzyme activity was determined using the standard assay procedure.

\section{Determination of Enzyme Inhibition and Kinetic Parameters}

The effects of various concentrations of compounds such as $\mathrm{NaCl}, \mathrm{NaBr}, \mathrm{EDTA}, \mathrm{DDC}$, L-cysteine, thiourea, ethanol and methanol on laccase activity was tested. $\mathrm{IC}_{50}$-values represent the concentration at which $50 \%$ inhibition was found.

The kinetic parameters of the laccase from $T$. hirsuta were determined on ABTS, syringaldazine (4-hydroxy-3,5-dimethoxybenzaldehyde azine), and DMP (2,6-dimethoxyphenol) as substrates. $K_{\mathrm{M}}$ and $V_{\max }$ were calculated according to a MichaelisMenten-like model by non-linear regression using the program MS Origin 4.10.

\section{Decolorization Reactions}

Tartrazine (CI Acid Yellow 23), and Indigo Carmine (CI Acid Blue 74) was supplied from Sigma Aldrich. Diamond Fast Brown (CI Mordant Brown 96/CI Mordant Brown 15), Diamond Black PV 200 (CI Mordant Black 9) and Lanaset Blue 2R (CI Acid Blue 225) were kindly donated from DyeStar. Anthrachinone sulfonic acid (ACSA) and 2,2'-azinobis (3ethylbenzthiazoline-6-sulfonic acid) diammonium salt (ABTS) were also supplied from Sigma.

$100 \mathrm{mg} \mathrm{L}^{-1}$ of Tartrazine, Diamond Fast Brown, Diamond Black PV 200, Indigo Carmine or Lanaset Blue $2 R$, respectively, were dissolved in citrate buffer at various pHs (ranging from 3 to 6). Decolorization experiments with laccase were started by adding laccase to a final enzyme activity of 17.9 nkat $\mathrm{mL}^{-1}$ in the cuvette. The reaction volume was $1.5 \mathrm{~mL}$. In the case of redox mediated reactions, catalytic amounts (as indicated below) of either ABTS, ACSA, or Lanaset Blue $2 R$ were added to the reaction mixtures prior to the laccase addition. The reactions were followed on-line in a UV/Vis spectrophotometer (U-2001, Hitachi) in the spectral range of 240 to $800 \mathrm{~nm}$ using a scan speed of $1200 \mathrm{~nm} \mathrm{~min}^{-1}$. Spectra were recorded every minute during the reaction until no more changes in the UV/Vis spectra were detected.

\section{Preparation of Model Azo-Dyes}

Anilines with substitutions of trifluoromethyl-, methyl-, chloro-, bromo-, and fluoro-groups at the $o-, m-$, and $p$-positions and 2,7-dihydroxynaphthalene-3,6-disulfonic acid disodium salt were supplied by Sigma Aldrich. Urea, sodium nitrite, and sodium hydroxide were from Merck, and 32\% hydrochloric acid was purchased from Riedel de Haen. Model azo dyes were synthesized from the corresponding aromatic amines in two steps as described elsewhere (Kandelbauer et al., 2004a). Precipitation of the dyes was facilitated by acidification with hydrochloric acid. For purification, the dyes were recrystallized from hot water and freeze-dried. The purity of the model azo-dyes was confirmed using a method based on the reduction of the azo linkage by excess of sodium dithionite as described in (Maier et al., 2004). The molar extinction coefficients $\left(\varepsilon_{M}\right)$ of the dyes were determined by measuring the absorbance at the wavelength of maximum absorbance $\left(\lambda_{\max }\right)$ of each dye. Molar extinction coefficients were determined by linear regression.

\section{Decolorization of Model Azo-Dyes}

In a total volume of $3 \mathrm{~mL}$ in a cuvette $0.1 \mathrm{mg} \mathrm{mL}^{-1}$ of a model dye was dissolved in citric acid buffer ( 25 $\mathrm{mM}$, at $\mathrm{pH}$ 3.75). Redox mediator ABTS (0.091 mM) 
was added to the solution and the decolorization was started by addition of $0.1 \mathrm{~mL}$ of laccase (178. 9 nkat $\mathrm{mL}^{-1}$ ). Alternatively, ABTS was enzymatically converted to the ABTS radical cation using an immobilized laccase. Subsequently, the radical cation was added to solutions of the model dyes and decolorization was performed without any laccase present in the cuvette. All reactions were followed by visible spectrophotometry, using the wavelength range from 300 to $600 \mathrm{~nm}$. The Vis-spectra of the reaction mixtures were mathematically deconvoluted using calibration functions for the molar absorptivities of all known compounds (dye, ABTS, ABTS radical cation) present in the mixture within the wavelength range studied. For kinetic analysis, the initial rates at various concentrations of dye at the respective absorbance maxima $\lambda_{\max }$ were used. All decolorizations followed a kinetic profile similar to the Michaelis-Menten profile. The kinetic parameters $V_{\max }^{\mathrm{app}}$ and $K_{\mathrm{M}}^{\mathrm{app}}$ were determined by nonlinear curve fitting using the Computer program MS Origin 4.10. In order to deduce a quantitative relationship between the dye molecular structure and its rate in laccase-catalyzed oxidation, the Hammett-linear free energy relationship was used, as given by Eq. (1):

$$
\left(\log V_{\max } / \log V_{\max , 0}\right)=\sigma+\rho, \text { where }
$$

$V_{\max }=$ maximal velocity for each dye

$V_{\max , 0}=$ maximal velocity for the dye without substituent

$\sigma=$ empirical constants calculated for all the substituents from a reference reaction,

$\rho=$ Hammett linear correlation parameter.

\section{RESULTS}

\section{Purification and Characterisation of the Laccase from T. hirsuta IMA2002}

A laccase from T. hirsuta IMA2002 was purified to electrophoretic homogeneity using anion exchange and size exclusion chromatography with a yield of $59.2 \%$. According to native PAGE, the isolated enzyme is the only laccase produced by this organism. The laccase had a molecular mass of $62 \mathrm{kDa}$ and the isoelectric point at $\mathrm{pH}$ 7. The laccase had an optimum $\mathrm{pH}$ of 3.0 and an optimum temperature of $55^{\circ} \mathrm{C}$. The laccase was quite stable at $30^{\circ} \mathrm{C}$ and $\mathrm{pH} 4.0$ with a half-life of more than 100 hours (Table I). After 15 minutes of incubation at $90^{\circ} \mathrm{C}$ and $\mathrm{pH} 4.0$ the laccase lost $50 \%$ of its activity.

The laccase from T. hirsuta IMA2002 tolerated high concentrations of ethanol and methanol but it was strongly inhibited by DDC, L-cysteine and thiourea (Table II). The catalytic efficiency of the laccase was
TABLE I Temperature and $\mathrm{pH}$ stabilities of the laccase obtained from T. hirsuta IMA2002

\begin{tabular}{llc}
\hline$T\left({ }^{\circ} \mathrm{C}\right)$ & $\mathrm{pH}$ & Half-life $(\mathrm{h})$ \\
\hline 30 & 2.0 & 9 \\
30 & 3.0 & 88 \\
30 & 4.0 & 107 \\
30 & 5.0 & 41 \\
30 & 6.0 & $<1$ \\
40 & 4.0 & 67 \\
50 & 4.0 & 29 \\
60 & 4.0 & 11 \\
70 & 4.0 & 2 \\
80 & 4.0 & $17 \mathrm{~min}$ \\
90 & 4.0 & $15 \mathrm{~min}$ \\
\hline
\end{tabular}

highest on syringaldazide and decreased in the order ABTS and DMP (Table III).

\section{Decolorization of Commercial Dyes}

The laccase was assayed for its versatility in dye decolorization using the commercial dyes Diamond Fast Brown, Indigo Carmine, Lanaset Blue 2R, Diamond Black PV 200 and Tartrazine. The chemical structures of the commercial dyes are shown in Fig. 1. The first four dyes were rapidly decolorized at $\mathrm{pH}$ 4.5 without the assistance of any mediator while Tartrazine was neither oxidized with laccase alone nor in the presence of ABTS or ACSA under analogous reaction conditions.

Interestingly, decolorization of Diamond Fast Brown was never complete but a solution of pale brownish color was obtained. Decolorization of Diamond Fast Brown and Tartrazine were performed at various $\mathrm{pH}$-values $(\mathrm{pH} \mathrm{3,4}, 5$, and 6) using either laccase alone or in combination with various additives at the same molar levels. The fastest transformation rates for Diamond Fast Brown were found at around $\mathrm{pH} 4$. The spectral time course of laccase-catalysed Diamond Fast Brown decolorisation at $\mathrm{pH} 4$ without any mediators is shown in Fig. 2a. For comparison, the UV/Vis spectral time

TABLE II Inhibition of the laccase from T. hirsuta IMA2002

\begin{tabular}{ll}
\hline Compound & $\mathrm{IC}_{50 \%}(\mathrm{mM})$ \\
\hline $\mathrm{NaCl}$ & 55 \\
$\mathrm{NaBr}$ & $>200$ \\
$\mathrm{NaF}$ & 1.5 \\
$\mathrm{NaN}_{3}$ & 0.14 \\
$\mathrm{KCN}$ & 0.12 \\
EDTA & $>300$ \\
Triton X-100 & No inhibition \\
DDC & 1.5 \\
L-Cysteine & $>0.1$ \\
Tyrosine & No inhibition \\
Thiourea & $>8.0$ \\
Ethanol & $>75 \%$ \\
Methanol & $>71 \%$ \\
Hexane & No inhibition \\
\hline
\end{tabular}

*DDC, diethyldithiocarbamate. 
TABLE III Specificity of the laccase from T. hirsuta on different substrates

\begin{tabular}{lcc}
\hline Substrate & $K_{\mathrm{M}}(\mu \mathrm{M})$ & $K_{\text {cat }}\left(\mathrm{s}^{-1}\right)$ \\
\hline ABTS & 75 & 64 \\
Syringaldazide & 12 & 83 \\
DMP & 37 & 54 \\
\hline
\end{tabular}

course of the same reaction performed in the presence of $0.025 \mathrm{mM}$ ABTS is depicted in Fig. $2 \mathrm{~b}$. Decolorization proceeded much faster in the presence of the mediator. Moreover, decolorization in the visible range of the spectrum was much more efficient when ABTS was used reflecting the greater extent of laccase-catalyzed oxidation. When Diamond Fast Brown transformation was performed in the presence of $0.025 \mathrm{mM}$ ACSA, a similar spectral time course was observed as with ABTS (data not shown). When another dye was used as the redox mediating compound, Lanaset Blue $2 \mathrm{R}$, the rates and extents of decolorization were, again, enhanced significantly compared to the unmediated reaction, as illustrated in Fig. 2c. ABTS was the most efficient mediator.

The relative decolorization rates of the reactions are shown in Table IV. The time course at the absorbance maximum at $\lambda_{\max }=550 \mathrm{~nm}$ of Diamond Fast Brown transformation is shown in Fig. 3. Evidently, there are two phases in dye degradation. Since Diamond Fast Brown consists of two different azodyes, the initial reaction rates, $v_{1}$, were attributed to the first compound. The rate for the decolorization of the second compound, $v_{2}$, was estimated by linear regression after the kink in the decolorization profile (see Fig. 3), based on the assumption that at this time the overall reaction rate was governed by the transformation of the second component of Diamond Fast Brown. Provided that the molar extinction coefficients of the two azo compounds comprising Diamond Fast Brown are of the same<smiles>O=C(O)c1nn(-c2ccc([N+](=O)[O-])cc2)c(C(=O)O)c1/N=N/c1cc([N+](=O)[O-])cc(Cl)c1O</smiles><smiles>C#Cc1cc(C)c(CNC(=O)CCl)c(C)c1-c1cc([O-])c(N)c2c1C(=O)c1ccccc1C2=O</smiles><smiles>Cc1nn(-c2ccc(O)cc2)c(O)c1/N=N/c1cc([N+](=O)[O-])cc(Cl)c1O</smiles><smiles>CCc1cccc2c(O)c(/N=N/c3cc([N+](=O)[O-])cc(Cl)c3O)ccc12</smiles><smiles>[CH]</smiles><smiles>O=[N+]([O-])c1ccc(O)c(/N=N/c2ccc3c(O)cccc3c2O)c1</smiles>

FIGURE 1 Structures of the commercial dyes used in this study. Tartrazine, I, (CI Acid Yellow 23); Diamond Fast Brown, II, (CI Mordant Brown 96/CI Mordant Brown 15); Lanaset Blue 2R, III, (CI Acid Blue 225), Indigo Carmine, IV, (CI Acid Blue 74), and Diamond Black PV 200, V, (CI Mordant Black 9). 


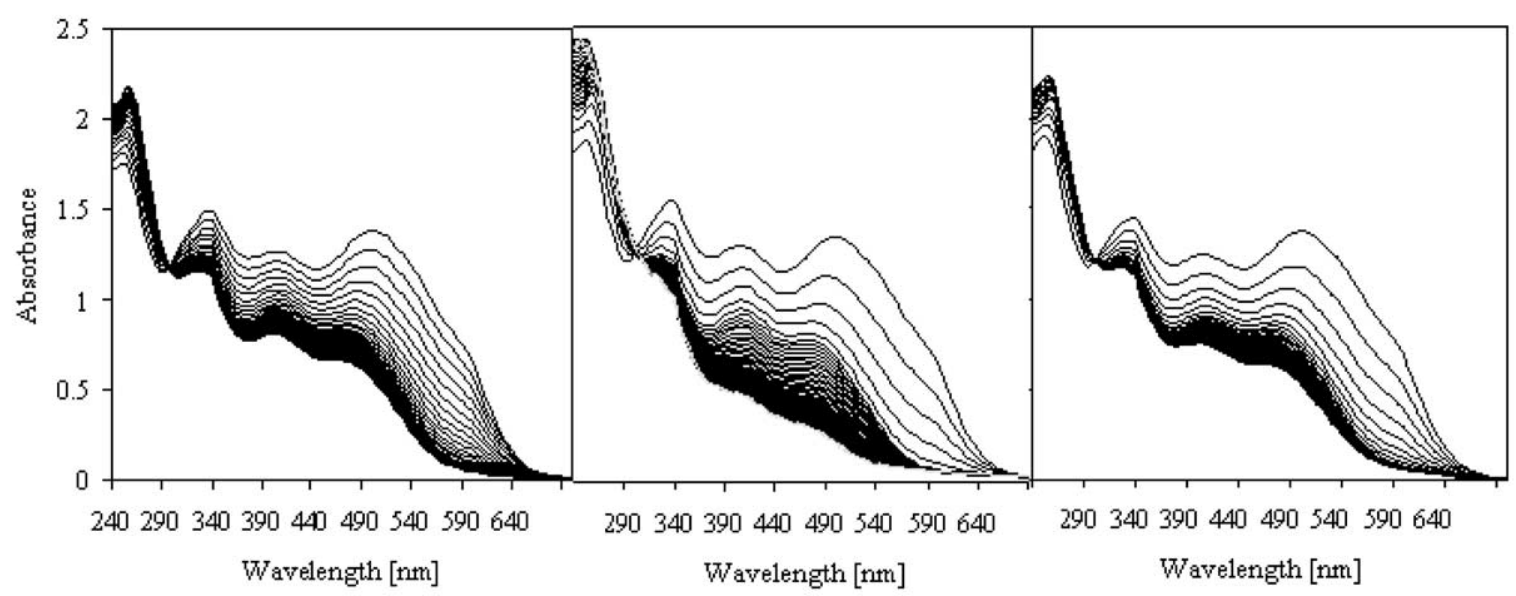

FIGURE 2 Laccase-catalysed transformation of Diamond Fast Brown as reflected by on-line UV-Vis spectroscopic measurements. Reaction conditions: (A) $100 \mathrm{mg} \mathrm{L}^{-1}$ dye, 17.9 nkat mL $\mathrm{mL}^{-1}$ laccase (citrate buffer, $\mathrm{pH} 4$ at $25^{\circ} \mathrm{C}$ ); (B) $100 \mathrm{mg} \mathrm{L}^{-1} \mathrm{dye} 17.9 \mathrm{nkat}_{\mathrm{mL}}^{-1}$ laccase (citrate buffer, $\mathrm{pH} 4$ at $25^{\circ} \mathrm{C}$ ), and (C) $0.025 \mathrm{mmol} \mathrm{L}^{-1} \mathrm{ABTS} ; 100 \mathrm{mg} \mathrm{L}^{-1}$ dye, 17.9 nkat $\mathrm{mL}^{-1}$ laccase (citrate buffer, $\mathrm{pH} 4$ at $25^{\circ} \mathrm{C}$ ), and $0.025 \mathrm{mmol} \mathrm{L}^{-1}$ Lanaset Blue $2 \mathrm{R}$. The lines indicate a loss in spectral absorbance per minute over a period of 30 minutes.

order of magnitude, the first component is degraded much faster than the second.

\section{Decolorization of Model Azo-Dyes}

Twenty-two structurally closely related model azodyes based on the molecular framework of 2,7dihydroxy-1-phenylazonaphthalene-3,6-disulfonic acid were synthesized and subjected to laccasecatalyzed oxidation, both with and without the redox mediator ABTS. The model dyes only differed in nature and position of the substituent on the phenyl ring which carried either a single methyl $\left(-\mathrm{CH}_{3}\right)$, trifluoromethyl $\left(-\mathrm{CF}_{3}\right)$, fluoro $(-\mathrm{F})$, chloro $(-\mathrm{Cl})$, bromo $(-\mathrm{Br})$, nitro $\left(-\mathrm{NO}_{2}\right)$, or a hydroxy $(-\mathrm{OH})$ group in the ortho-, meta-, or para-position with respect to the azo linkage. All dyes had a broad absorbance maximum between 480 and $490 \mathrm{~nm}$ and appeared brownish-orange. The chemical structures of the model dyes are shown in Fig. 4.

Enzymatic degradation without the assistance of ABTS as an electron mediator took place only with the hydroxy-substituted model azo-dyes. All other dyes except for the trifluoromethyl-substituted ones were only degraded when catalytic amounts of
ABTS were present in the reaction mixture. Trifluoromethyl-substituted dyes were not decolorized at all whereas the other model azo-dyes were decolorized to more than $80 \%$ within the first 30 minutes of incubation with the laccase/ABTS system. At constant dye and laccase activities, an increase in ABTS concentration resulted in an increase in decolorization rates. The rates also directly depended on the amount of laccase added.

All dyes that were decolorized by the laccase/ ABTS combination were also decolorized to some extent by the activated mediator species alone, the ABTS radical cation without the laccase being present in the system. For this experiment, an immobilized form of the laccase was used to generate the radical cation. After removing the enzyme by filtration, the dark green solution of the activated mediator species was added to the dye solutions. However, decolorizaton in this case never proceeded towards completion because no regeneration of the reduced mediator took place. The kinetic parameters $V_{\max }^{\mathrm{app}} K_{\mathrm{M}}^{\mathrm{app}}$, and $k_{\text {cat, dye }}$ for the oxidation of the various model azo-dyes with the laccase/ABTS catalytic system are presented in Table V.

TABLE IV Relative reaction rates for the Diamond Fast Brown transformation by laccase and laccase/mediator systems as indicated by the decrease in the absorbance at $\lambda_{\max }=550 \mathrm{~nm}$. Reaction mixtures contained either no mediator or $0.025 \mathrm{mM}$ ABTS, ACSA, or Lanaset Blue 2R, respectively (except as indicated). All reactions were performed at $\mathrm{pH} 4$ and $25^{\circ} \mathrm{C} . v_{1}, v_{2}=$ rates of transformation of compounds 1 and 2 of Diamond Fast Brown, respectively; $v_{1}$, and $v_{2}$ corresponding rate accelerations with respect to the unmediated reaction (for definition see text)

\begin{tabular}{|c|c|c|c|c|}
\hline Reaction & $v_{1}\left(\mathrm{Abs} \min ^{-1}\right)$ & $v_{2}\left(\mathrm{Abs}_{\mathrm{min}}^{-1}\right)$ & $r_{\mathrm{acc}, 1}$ & $r_{\text {acc, } 2}$ \\
\hline Laccase, no mediator & $-1.91 \times 10^{-3}$ & $-3.99 \times 10^{-3}$ & 1 & 1.0 \\
\hline Laccase/ABTS & $-2.14 \times 10^{-1}$ & $-2.03 \times 10^{-2}$ & 111.9 & 5.1 \\
\hline Laccase/ACSA & $-1.79 \times 10^{-1}$ & $-5.34 \times 10^{-3}$ & 93.7 & 1.3 \\
\hline Laccase/ACSA (0.05 mM) & $-1.79 \times 10^{-1}$ & $-6.56 \times 10^{-3}$ & 93.5 & 1.6 \\
\hline Laccase/Lanaset Blue 2R & $-1.89 \times 10^{-1}$ & $-9.13 \times 10^{-3}$ & 99.1 & 2.3 \\
\hline
\end{tabular}




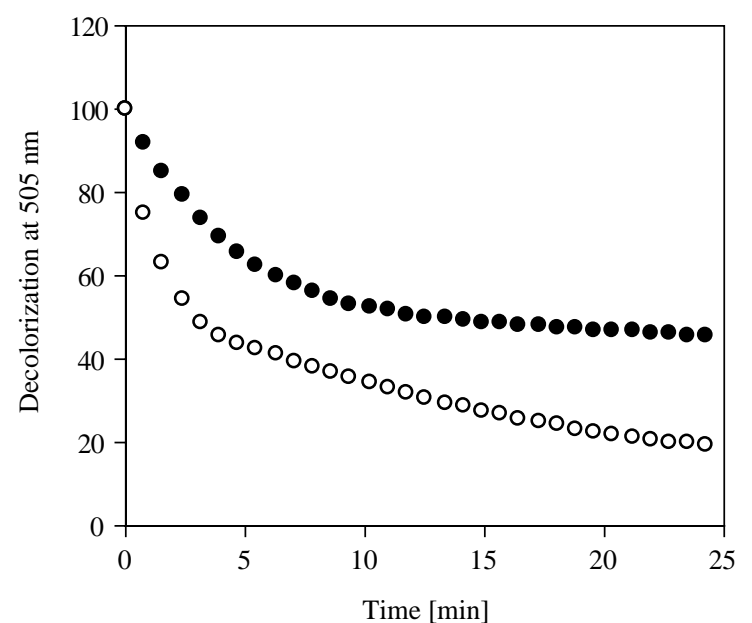

FIGURE 3 Time course at the absorbance at $\lambda_{\max }=550 \mathrm{~nm}$ of Diamond Fast Brown transformation using laccase from T. hirsuta (black circles) and laccase/ABTS (white circles).

Methyl substituents had slightly increased values for $V_{\max }^{\mathrm{app}}$ in the order ortho > para > meta. The highest specificity constant was observed with the derivative carrying a hydroxyl substituent in the para-position. Most of the substrates became less susceptible towards oxidation upon substitution. Only electron donating groups had a positive effect. Halogens generally had a negative effect. Within a series of halogens, the lowest values for $V_{\max }^{\mathrm{app}}$ were observed with fluorine containing compounds. Whereas no clear preference was detected for the ortho- and para-positions, meta-substituted compounds always displayed lower $V_{\max }^{\mathrm{app}}$ values. Trifluoro-substituted dyes were not attacked at all.

In order to obtain a quantitative structure-reactivity relationship for the dye oxidation rates catalyzed by the laccase/mediator system, a correlation analysis relating a structural parameter such as the Hammett-parameter with the measured apparent kinetic parameters was performed. In Fig. 5 the results of the Hammett correlation plot of the initial reaction rates with the laccase/ABTS system are shown. Evidently, the structural influence of the structural variation fits the free linear energy relationship very well with a resulting Hammett correlation coefficient of $\rho=0.44$.

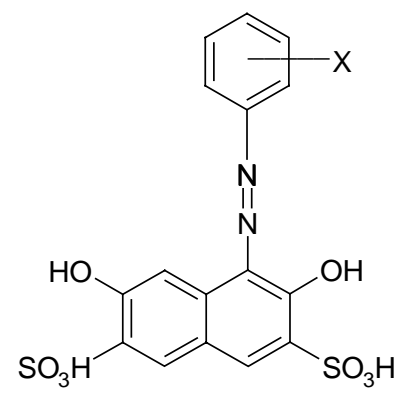

FIGURE 4 Structures of the model azo-dyes used in this study. $\mathrm{X}=-\mathrm{H},-\mathrm{CH}_{3},-\mathrm{CF}_{3},-\mathrm{F},-\mathrm{Cl},-\mathrm{Br},-\mathrm{NO}_{2},-\mathrm{OH}$.

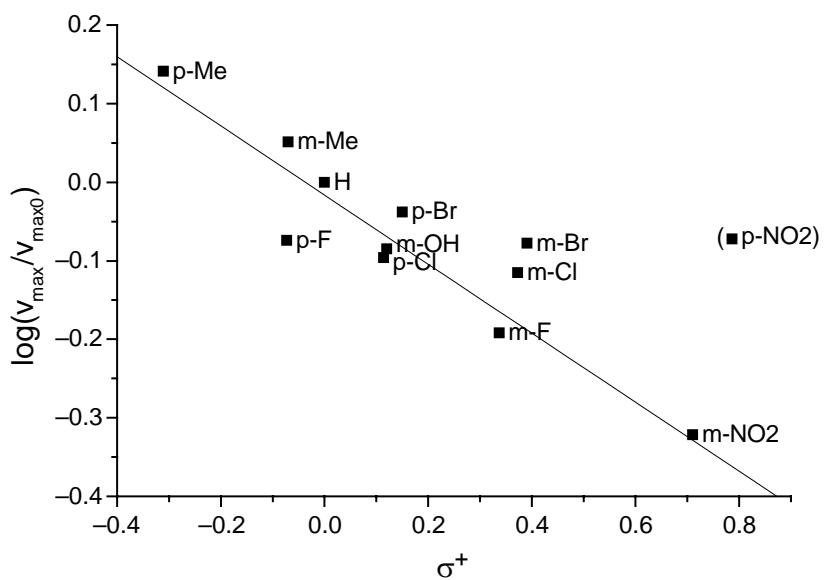

FIGURE 5 Hammett plot for the decolorisation of various model dyes with a laccase from T. hirsuta and ABTS.

\section{DISCUSSION}

A few laccases have been isolated previously from different strains of T. hirsuta. The molecular masses of these enzymes lie in a range between 55 and 82 $\mathrm{kDa}$. The laccase from T. hirsuta IMA2002 purified in this study had a molecular mass of $62 \mathrm{kDa}$ compared to 80-82 kDa (Shin and Kim, 1998), $73 \mathrm{kDa}$ (Shin and Lee, 2000), $55 \mathrm{kDa}$ (Koroljovaskorobogatko et al ., 1998) reported for laccases isolated from different strains of T. hirsuta. In agreement with data from the literature the laccase from T. hirsuta IMA2002 was strongly inhibited by DDC, L-cysteine and thiourea (Johannes and Majcherczyk, 2000b). As a common feature of laccases (Abadulla et al., 2000), out of the halides tested $\mathrm{NaF}$ was the strongest inhibitor.

In agreement with data from the literature the laccase from T. hirsuta IMA2002 oxidised syringaldazide more efficiently than ABTS and DMP. In addition to these common laccase substrates the laccase also oxidized a number of common textile dyes, although many of these required addition of mediators. The purified laccase from $T$. hirsuta decolorized the structurally diverse commercial dyes Indigo Carmine (CI Acid Blue 74, indigoid dye), Lanaset Blue 2R (CI Acid Red 224, anthrachinoid dye), Diamond Black PV 200 (CI Mordant Black 9, azo-dye) and Diamond Fast Brown (CI Mordant Brown 96/CI Mordant Brown 15, azo-dyes). While the rate and extent of decolorization of the latter dye was significantly enhanced by the presence of different types of mediators, another azo dye, Tartrazine (CI Acid Yellow 23) was not oxidized at all.

Diamond Fast Brown consists of two azo dyes, which differ greatly in their biodegradability. From the results of the present study, it can not yet positively be deduced whether the heterocyclic or the naphthyl component is more susceptible towards laccase catalysis. However, it is very plausible 
TABLE V Laccase/ABTS-catalyzed oxidation of model azo-dyes (CS, characteristic substituent; $M_{\mathrm{W}}$, molecular weight; $V_{\max }^{\mathrm{app}}, K_{\mathrm{M}}^{\mathrm{app}}$, and $k_{\text {cat, dye }}=$ apparent kinetic constants)

\begin{tabular}{lcccc}
\hline $\mathrm{CS}$ & $M_{\mathrm{W}}\left(\mathrm{g} \mathrm{mol}^{-1}\right)$ & $V_{\text {max }}^{\text {app }}\left(\mathrm{mM} \mathrm{s}^{-1}\right)$ & $K_{\mathrm{M} p}^{\text {app }}(\mathrm{mM})$ & $k_{\text {cat, dye }}\left(\mathrm{s}^{-1}\right)$ \\
\hline $\mathrm{H}$ & 468 & $2.01 \mathrm{E}-04$ & $1.12 \mathrm{E}-02$ & $1.79 \mathrm{E}-02$ \\
$o-\mathrm{CH}_{3}$ & 482 & $2.85 \mathrm{E}-04$ & $3.35 \mathrm{E}-02$ & $8.51 \mathrm{E}-03$ \\
$m-\mathrm{CH}_{3}$ & 482 & $2.26 \mathrm{E}-04$ & $2.35 \mathrm{E}-02$ & $9.62 \mathrm{E}-03$ \\
$p-\mathrm{CH}_{3}$ & 482 & $2.68 \mathrm{E}-04$ & $2.33 \mathrm{E}-02$ & $1.15 \mathrm{E}-02$ \\
$o-\mathrm{F}$ & 486 & $1.71 \mathrm{E}-04$ & $3.21 \mathrm{E}-02$ & $5.33 \mathrm{E}-03$ \\
$m-\mathrm{F}$ & 486 & $1.29 \mathrm{E}-04$ & $2.49 \mathrm{E}-02$ & $5.18 \mathrm{E}-03$ \\
$p-\mathrm{F}$ & 486 & $1.69 \mathrm{E}-04$ & $2.15 \mathrm{E}-02$ & $7.86 \mathrm{E}-03$ \\
$o-\mathrm{Cl}$ & 502 & $2.10 \mathrm{E}-04$ & $3.18 \mathrm{E}-02$ & $6.60 \mathrm{E}-03$ \\
$m-\mathrm{Cl}$ & 502 & $1.54 \mathrm{E}-04$ & $2.55 \mathrm{E}-02$ & $6.04 \mathrm{E}-03$ \\
$p-\mathrm{Cl}$ & 502 & $1.64 \mathrm{E}-04$ & $2.48 \mathrm{E}-02$ & $6.61 \mathrm{E}-03$ \\
$o-\mathrm{Br}$ & 547 & $1.86 \mathrm{E}-04$ & $3.92 \mathrm{E}-02$ & $4.74 \mathrm{E}-03$ \\
$m-\mathrm{Br}$ & 547 & $1.68 \mathrm{E}-04$ & $3.58 \mathrm{E}-02$ & $4.69 \mathrm{E}-03$ \\
$p-\mathrm{Br}$ & 547 & $2.00 \mathrm{E}-04$ & $5.73 \mathrm{E}-02$ & $3.49 \mathrm{E}-03$ \\
$o-\mathrm{NO} \mathrm{S}_{2}$ & 513 & $9.60 \mathrm{E}-05$ & $3.38 \mathrm{E}-02$ & $2.84 \mathrm{E}-03$ \\
$m-\mathrm{NO}{ }_{2}$ & 513 & $9.57 \mathrm{E}-05$ & $1.74 \mathrm{E}-02$ & $5.50 \mathrm{E}-03$ \\
$p-\mathrm{NO}_{2}$ & 513 & $1.81 \mathrm{E}-04$ & $7.80 \mathrm{E}-02$ & $2.32 \mathrm{E}-03$ \\
$o-\mathrm{OH}$ & 484 & $1.43 \mathrm{E}-04$ & $2.30 \mathrm{E}-02$ & $6.22 \mathrm{E}-03$ \\
$m-\mathrm{OH}$ & 484 & $1.65 \mathrm{E}-04$ & $2.50 \mathrm{E}-02$ & $6.60 \mathrm{E}-03$ \\
$p-\mathrm{OH}$ & 484 & $4.32 \mathrm{E}-03$ & $2.52 \mathrm{E}-02$ & $1.71 \mathrm{E}-01$ \\
$o-\mathrm{CF}_{3}$ & 536 & & No reaction & \\
$m-\mathrm{CF}_{3}$ & 536 & No reaction & \\
$p-\mathrm{CF}_{3}$ & 536 & & No reaction & \\
\hline
\end{tabular}

that the naphthyl dye is the compound preferably oxidized for the following reasons: (1) ortho-hydroxynaphthyl dyes were degraded very rapidly by laccase as found in previous studies when the substrate specificities of laccase towards structurally very similar Diamond Black PV 200 (Kandelbauer et al., 2004a) and various closely related derivatives of Diamond Black PV 200 (Kandelbauer et al., 2004b) were investigated. (2) Tartrazine, which is a heterocyclic azodye of very similar structure compared to the heterocyclic component of Diamond Fast Brown, was not attacked by the enzyme at all. The reason for the recalcitrant behaviour of Tartrazine may be that it contains two electron withdrawing carboxyl groups in the pyrazole ring which decrease the electron density at the basic structure common to both heterocyclic dyes. In contrast, the hydroxy and methyl groups present in the heterocyclic component of Diamond Fast Brown may increase the electron density in the pyrazole ring by their $+\mathrm{M}-$ effect, especially when deprotonated, and thereby also increase its susceptibility towards laccase catalysis.

Two structurally different types of mediator, ABTS and the anthrachinoid compound anthrachinone sulfonic acid (ACSA) both significantly enhanced the oxidation of Diamond Fast Brown whereas the oxidation of Tartrazine remained unaffected by the laccase/mediator systems. Lanaset Blue $2 \mathrm{R}$, a commercial textile dye containing a similar anthrachinoid structural fragment acted similarly to ACSA, enhancing the reaction rate by practically the same factor.

Unfortunately, the combination of laccase with anthrachinoid mediators possesses too little oxida- tive power to fully oxidize Diamond Fast Brown and the laccase/ABTS mixture still remains more effective in this case. However, this finding is still of great importance for enzyme remediation systems because it means that dyestuff mixtures containing redoxactive dyes in some cases may be more liable to laccase oxidation than solutions of pure dyes. Besides dyes themselves dye degradation products have been previously shown to act as mediators (Wong and Yu, 1999).

Little information is available in the literature quantitatively describing the effects of dye chemical structure on the reactivity towards laccase oxidation in presence of mediators. Thus, a set of twenty-two model azo-dyes of chemically very similar structure was synthesized and the kinetics of their laccasecatalyzed decolorization was studied.

Only two of the model substrates were readily oxidized by the laccase without any mediators present. They carried a hydroxy group either in the ortho or para position relative to the azo-bond and were the most reactive dyes also when the laccase was used in combination with the redox mediator ABTS. In a previous study with the same set of model dyes but using a laccase from Trametes modesta (Kandelbauer et al., 2004b), we had observed a similar behaviour. There too, the hydroxy-substituted dyes were the ones most susceptible towards enzyme action and were completely decolorized. In both cases, the oxidation of the hydroxy-substituted model dyes proceeded much more slowly when compared to the corresponding decolorization of some common commercial dyes of different chemical structure, Diamond Black PV 200 and Diamond 
Fast Brown (azo), Lanaset Blue 2R (anthrachinoid), or Indigo Carmine (indigoid).

Seventeen of the dyes $\left(-\mathrm{H}, o-, m-, p-\mathrm{CH}_{3},-\mathrm{F},-\mathrm{Cl}\right.$, $\left.-\mathrm{Br},-\mathrm{NO}_{2}, m-\mathrm{OH}\right)$ were only decolorized when ABTS was present in the reaction medium as a redox mediator. Thereby, we showed that the substrate specificity of laccases can significantly be broadened for the enzyme to accept a wide range of different substitutional patterns engineered on the otherwise same and enzymatically inert basic framework. Additionally, by using more than twenty two designed model dyes we were able to quantify the effects of the various substituents. All reactions were well described by Michaelis-Menten-like kinetics and the apparent kinetic constants $V_{\max }^{\mathrm{app}}$ and $K_{\mathrm{M}}^{\mathrm{app}}$ for the decolorization of each dye as well as the corresponding specificity constants $k_{\text {cat, dye }}$ were determined. We found that the Hammett free energy linear relationship could be successfully applied to the redox mediated laccase oxidation of azodyes and a structure-reactivity relationship could be established.

Electron-withdrawing substitutents generally were found to diminish reaction rates whereas electron-donating groups enhanced the susceptibility of the dye towards oxidative attack. This is in accordance with the underlying mechanism of ABTS mediation. ABTS mediated reactions proceed via an electron transfer mechanism (Fabbrini et al., 2002) and rates are thus strongly dependent on the redox potentials of the oxidized substrates. ABTS extends the substrate specificity of the laccase towards substrates of higher redox potentials.

However, three of the model dyes which were not oxidized. They carried a trifluoromethyl substituent either in the ortho, meta, or para position to the azolinkage. Apparently, the electron withdrawing effect of three fluorine atoms is strong enough to completely prevent the reaction.

In conclusion we have shown that in complex mixtures of dyes, some dyes can act as mediators. In addition, the relationship between dye structure and decolorization efficiency by laccase mediator systems can be described with the Hammett free energy linear relationship.

\section{Acknowledgements}

This study was supported by the European Projects BIOEFFTEX and OXITEX.

\section{References}

Abadulla, E., Tzanov, T., Costa, S., Robra, K.-H., Cavaco-Paulo, A. and Gübitz, G.M. (2000) Decolorization and detoxification of textile dyes with a laccase from Trametes hirsuta, Appl. Environ. Microbiol. 66, 3357-3362.

Barriere, F., Ferry, Y., Rochefort, D. and Leech, D. (2004) Targetting redox polymers as mediators for laccase oxygen reduction in a membrane-less biofuel cell, Electrochem. Commun. 6, 237 241.

Blanquez, P., Casas, N., Font, X., Gabarrell, X., Sarra, M., Caminal, G. and Vicent, T. (2004) Mechanism of textile metal dye biotransformation by Trametes versicolor, Water Res. 38, 21662172.

Böhmer, S., Messner, K. and Srebotnik, E. (1998) Oxidation of phenanthrene by a fungal laccase in the presence of 1hydroxybenzotriazole and unsaturated lipids, Biochem. Biophys. Res. Commun. 244, 233- 238.

Bourbonnais, R. and Paice, M.G. (1992) Demethylation and delignification of kraft pulp by Trametes versicolor laccase in the presence of 2,2'-azinobis-(3-ethylbenzthiazoline-6-sulphonate), Appl. Microbiol. Biotechnol. 36, 823-827.

Bradford, M.M. (1976) A rapid and sensitive method for the quantitation of microgram quantities of protein utilizing the principle of protein-dye binding, Anal. Biochem. 72, 248- 254.

Camarero, S., Garcia, O., Vidal, T., Colom, J., del Rio, J.C., Gutierrez, A., Gras, J.M., Monje, R., Martinez, M.J. and Martinez, A.T. (2004) Efficient bleaching of non-wood highquality paper pulp using laccase-mediator system, Enzyme. Microb. Technol. 35, 113- 120.

D'Annibale, A., Rita Stazi, S., Vinciguerra, V. and Giovannozzisermanni, G. (2000) Oxirane-immobilized Lentinula edodes laccase: stability and phenolics removal efficiency in olive mill wastewater, J. Biotechnol. 77, 265-273.

Davis, S. and Burns, R.G. (1992) Covalent immobilization of laccase on activated carbon for phenolic effluent treatment, Appl. Microbiol. Biotechnol. 37, 474- 479.

Dodor, D.E., Hwang, H.M. and Ekunwe, S.I.N. (2004) Oxidation of anthracene and benzo[a]pyrene by immobilized laccase from Trametes versicolor, Enzyme Microb. Technol. 35, 210- 217.

Eggert, C., Temp, U. and Eriksson, K.E. (1996) Laccase-producing white-rot fungus lacking lignin peroxidase and manganese peroxidase, Acs. Symp. Ser. 655, 130- 150.

Fabbrini, M., Galli, C. and Gentili, P. (2002) Comparing the catalytic efficiency of some mediators of laccase, J. Mol. Catal. B: Enzym. 16, 231-240.

Haars, A. and Huttermann, A. (1980) Function of laccase in the white rot fungus Fomes annosus, Arch. Microbiol. 125, 233237.

Johannes, C. and Majcherczyk, A. (2000a) Natural mediators in the oxidation of polycyclic aromatic hydrocarbons by laccase mediator systems, Appl. Environ. Microbiol. 66, 524-528.

Johannes, C. and Majcherczyk, A. (2000b) Laccase activity tests and laccase inhibitors, J. Biotechnol. 78, 193-199.

Jönsson, L.J., Palmqvist, E., Nilvebrant, N.O. and Hahnhagerdal, B. (1998) Detoxification of wood hydrolysates with laccase and peroxidase from the white-rot fungus Trametes versicolor, Appl. Microbiol. Biotechnol. 49, 691-697.

Kandelbauer, A., Erlacher, A., Cavaco-Paulo, A. and Gübitz, G.M. (2004a) Laccase-catalyzed decolorization of the synthetic azodye Diamond Black PV and of some structurally related derivatives, Biocatal. Biotrans., in press.

Kandelbauer, A. and Gübitz, G.M. (in press), Bioremediation for the decolorization of textile dyes, a review, In: Lichtfouse, E., Dudd, S. and Robert, D., eds, Environmental Chemistry (Springer-Verlag, Heidelberg).

Kandelbauer, A., Maute, O., Kessler, R., Erlacher, A. and Gübitz, G.M. (2004b) Study on dye decolorization in an immobilized laccase enzyme-reactor using on-line spectroscopy, Biotechnol. Bioeng. 87, $552-563$.

Keum, Y.S. and Li, Q.X. (2004) Fungal laccase-catalyzed degradation of hydroxy polychlorinated biphenyls, Chemosphere 56, $23-30$.

Koroljovaskorobogatko, O.V., Stepanova, E.V., Gavrilova, V.P., Morozova, O.V., Lubimova, N.V., Dzchafarova, A.N., Jaropolov, A.I. and Makower, A. (1998) Purification and characterization of the constitutive form of laccase from the basidiomycete Coriolus hirsutus and effect of inducers on laccase synthesis, Biotechnol. Appl. Biochem. 28, 47-54.

Lowry, O.H., Rosebrouch, N.J., Farr, A.L. and Randall, R.J. (1951) Protein measurement with the Folin Phenol reagent, J. Biol. Chem. 193, 263- 275.

Maier, J., Kandelbauer, A., Erlacher, A., Cavaco-Paulo, A. and Gübitz, G.M. (2004) A new alkali-thermostable azoreductase 
from Bacillus sp. strain SF, Appl. Environ. Microbiol. 70, 837844.

Niku-Paavola, M.-L. and Viikari, L. (2000) Enzymatic oxidation of alkenes, J. Mol. Catal. B: Enz. 10, 435-444.

Nyanhongo, G.S., Gomes, J., Gubitz, G.M., Zvauya, R., Read, J. and Steiner, W. (2002) Decolorization of textile dyes by laccases from a newly isolated strain of Trametes modesta, Water Res. 36, 1449-1456.

Paice, M.G., Bourbonnais, R., Reid, I.D., Archibald, F.S. and Jurasek, L. (1995) Oxidative bleaching enzymes: a review, J. Pulp. Pap. Sci. 21, J280- J284.

Reyes, P., Pickard, M.A. and Vazquez-Duhalt, R. (1999) Hydroxybenzotriazole increases the range of textile dyes decolorized by immobilized laccase, Biotechnol. Lett. 21, 875-880.

Rodriguez, E., Nuero, O., Guillen, F., Martinez, A.T. and Martinez, M.J. (2004) Degradation of phenolic and non-phenolic aromatic pollutants by four Pleurotus species: the role of laccase and versatile peroxidase, Soil. Biol. Biochem. 36, 909-916.

Ryan, S.E., Schnitzhofer, W., Tzanov, T., Cavaco-Paulo, A. and Gübitz, G.M. (2003) An acid-stable laccase from Sclerotium rolfsii with potential for wool dye decolourization, Enzyme Microb. Technol. 33, 766-774.

Shin, K.S. and Kim, H.M. (1998) Properties of laccase purified from nitrogen limited culture of white-rot fungus Coriolus hirsutus, Biotechnol. Technol. 12, 101-104.
Shin, K.S. and Lee, Y.J. (2000) Purification and characterization of a new member of the laccase family from the white-rot basidiomycete Coriolus hirsutus, Arch. Biochem. Biophys. 384, $109-115$.

Tavares, A.P.M., Gamelas, J.A.F., Gaspar, A.R., Evtuguin, D.V. and Xavier, A.M.R.B. (2004) A novel approach for the oxidative catalysis employing polyoxometalate-laccase system: application to the oxygen bleaching of kraft pulp, Catal. Commun. $5,485-489$.

Thurston, C.F. (1994) The structure and function of fungal laccases, Microbiology 140, 19- 26.

Tychanowicz, G.K., Zilly, A., de Souza, C.G.M. and Peralta, R.M. (2004) Decolourisation of industrial dyes by solid-state cultures of Pleurotus pulmonarius, Process Biochem. 39, 855859.

Ullah, M.A., Bedford, C.T. and Evans, C.S. (2000) Reactions of pentachlorophenol with laccase from Coriolus versicolor, Appl. Microbiol. Biotechnol. 53, 230- 234.

Wong, Y. and Yu, J. (1999) Laccase-catalyzed decolorization of synthetic dyes, Water Res. 33, 3512-3520.

Yaropolov, A.I., Skorobogatko, O.V., Vartanov, S.S. and Varfolomeyev, S.D. (1994) Laccase properties, catalytic mechanism, and applicability, Appl. Biochem. Biotechnol. 49, 257280 . 